\title{
Hypercalcemia after discontinuation of long-term denosumab treatment
}

\section{Anne Sophie Koldkjær Sølling ${ }^{1,2}$, Torben Harsløf ${ }^{1}$, Andreas Kaal ${ }^{3}$,}

Lars Rejnmark $^{1}$, Bente Langdahl ${ }^{1}$

${ }^{1}$ Department of Endocrinology and Internal Medicine, Aarhus University Hospital, Denmark, ${ }^{2}$ Department of Nuclear Medicine, Aarhus University Hospital, Denmark, ${ }^{3}$ Department of Medicine, Regional Hospital Horsens, Denmark

\section{E-mail: annesoel@rm.dk}

\section{INTRODUCTION}

\section{AIMS}

Denosumab (Dmab) is an anti-resorptive agent used to treat osteoporosis

After discontinuation of Dmab bone resorption increases, and the bone mass gained during therapy declines

Treatment with Dmab is considered to be reversible

\section{CASE DESCRIPTION AND DISCUSSION}

A 67-year-old woman with osteoporosis participated in the FREEDOM-trial from October 2004 to May 2014

She was treated with Dmab $60 \mathrm{mg}$ subcutaneously every 6 months

In November 2014 biochemistry showed an increased p-ionized calcium (I-Ca) $1.64 \mathrm{mmol} / \mathrm{l}$ (1.18-1.32 mmol/l), suppressed p-parathyroid hormone (PTH) $1.6 \mathrm{pmol} / \mathrm{l}(1.6-6.9 \mathrm{pmol} / \mathrm{l})$, and a decreased estimated glomerular filtration rate (eGFR) of $58 \mathrm{~mL} / \mathrm{min}(>60 \mathrm{~mL} / \mathrm{min})$ (table 1)

- Additional investigations including a CT scan of the thorax, abdomen and pelvis, a bone scintigraphy, an MRI scan of both ankles and blood tests showed no evidence of malignancy, humoral hypercalcemia of malignancy, granulomatous disease, vitamin A intoxication or multiple myeloma.

The hypercalcemia was unlikely to be attributed to her medication.

- The patient initiated treatment with Alendronat 70mg once weekly in January 2015.
Bone turnover markers (BTMS) were not investigated until April 2015. Nevertheless, BTMs were highly elevated and despite treatment with bisphosphonate remained elevated although decreasing

During treatment with Dmab the patient had been normocalcemic most of the time for the first five years. Thereafter, total $p$-calcium was with one exception above the reference range and increasing.

We speculate that the marked increase in BTMs after discontinuation of long-term Dmab is caused by a counter regulatory increased production of RANKL.

- The increased production of RANKL and potentially accumulation of RANKL will lead to a rebound activation of bone turnover, when the effect of the last denosumab administration wears of. This may cause hypercalcemia.

- If Dmab is administered again after 6 months bone resorption will effectively be inhibited again but in a situation like our case, where Dmab is not administered after 6 months, high bone turnover and hypercalcemia may persist for months.

\begin{tabular}{|c|c|c|c|c|c|c|c|c|c|c|c|}
\hline & Dates & & & & & & & & & & \\
\hline $\begin{array}{l}\text { Parameter } \\
\text { (reference range) }\end{array}$ & $\begin{array}{l}\text { May 5th } \\
2014\end{array}$ & $\begin{array}{l}\text { Aug. 8th } \\
2014\end{array}$ & $\begin{array}{c}\text { Nov. 25th } \\
2014\end{array}$ & $\begin{array}{l}\text { Dec. 22nd } \\
2014\end{array}$ & $\begin{array}{l}\text { Jan. 1st } \\
2015\end{array}$ & $\begin{array}{l}\text { Jan. 8th } \\
2015\end{array}$ & $\begin{array}{l}\text { Mar. 16th } \\
2015\end{array}$ & $\begin{array}{l}\text { April 1st } \\
2015\end{array}$ & $\begin{array}{l}\text { May 20th } \\
2015\end{array}$ & $\begin{array}{l}\text { May 27th } \\
2015\end{array}$ & $\begin{array}{l}\text { Sep. 2nd } \\
2015\end{array}$ \\
\hline $\begin{array}{l}\mathrm{s}-\mathrm{I}-\mathrm{Ca}(\mathrm{mmol} / \mathrm{L}) \\
(1.18-1.32)\end{array}$ & & & & 1.64 & 1.6 & 1.57 & 1.41 & 1.29 & 1.31 & 1.32 & 1.26 \\
\hline $\begin{array}{l}\text { p-PTH (pmol/L) } \\
(1.6-6.9)\end{array}$ & & & 1.6 & 1.7 & & & 2.5 & 3.9 & 49 & 4.3 & 4.2 \\
\hline $\begin{array}{l}\mathrm{p}-\mathrm{CTX}(\mu \mathrm{g} / \mathrm{L}) \\
(0.03-0.83)\end{array}$ & & & 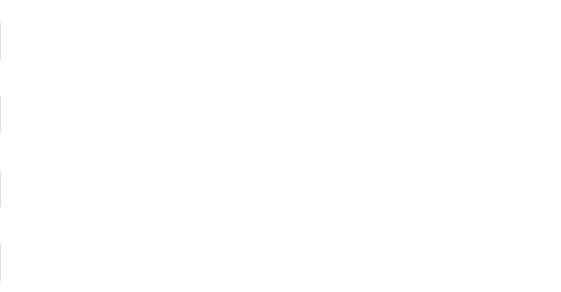 & & & & & 1.47 & & 1.54 & 1.12 \\
\hline $\begin{array}{l}\text { p-P1NP }(\mu \mathrm{g} / \mathrm{L}) \\
(13-116)\end{array}$ & & & & & & & & 304 & & 288 & 203 \\
\hline $\begin{array}{l}\text { p-ALP }(\mu \mathrm{g} / \mathrm{L}) \\
(5.5-27.1)\end{array}$ & & & & & & & & 100 & & 79 & 60 \\
\hline $\begin{array}{l}\text { p-eGFR }(\mathrm{mL} / \mathrm{min}) \\
(>60)\end{array}$ & 83 & $>90$ & 58 & 52 & 50 & 59 & 80 & 74 & 78 & & 79 \\
\hline $\begin{array}{l}\text { p-phosphate }(\mathrm{mmol} / \mathrm{L}) \\
(0,76-1,41)\end{array}$ & & & & 0.94 & & & & 0.84 & 0.89 & & 0.88 \\
\hline p-albumin $(g / L)$ & & & & 41 & & & & & 41 & & 41 \\
\hline
\end{tabular}

41

41

41

Table 1. The development of bone related biochemistry from May 2014 to September 2015. Results on the left hand side of the dashed line are results obtained prior to the discovery of the patient's hypercalcemia. s: serum, p: plasma, CTX: C-telopeptide of type I collagen, P1NP: N-terminal propeptide of type 1 procollagen, ALP: bone-specific alkaline phosphatase.

\section{CONCLUSION}

- We report the first association between discontinuation of long-term Dmab therapy for the treatment of osteoporosis and hypercalcemia with renal impairment and marked increase in BTMs.

Our findings emphasize the need to develop evidence-based guidelines on discontinuation of treatment with Dmab in order to both avoid side-effects of long-term therapy and side effects of discontinuation as well as to preserve BMD.

\section{DISCLOSURE}

Anne Sophie Koldkjær Sølling and Andreas Kaal have nothing to declare. Torben Harsløf received lecture fees from Amgen. Bente Langdahl is a consultant for MSD, Amgen, Eli Lilly, and UCB and has received lecture fees from MSD, Eli Lilly, and Amgen. Lars Rejnmark has received lecture fees from Amgen and Eli Lilly and has consulted for NPS Pharma. 